\title{
CAPACITAÇÃO EM EDUCAÇÃO A DISTÂNCIA: REFLEXÕES DE UM CURSISTA
}

Rosa Helena Silva Souzaㄹ, Liliana Müller Larocca ${ }^{2}$, Adeli Regina Prizybicien de Medeiros ${ }^{3}$

RESUMO: Trata-se de uma reflexão acerca da importância do processo de ensino aprendizagem on-line para a formação de tutores em Educação a distância, segundo a percepção do cursista. O estudo destaca o relato da experiência de um aluno inserido nesta modalidade de ensino; sua visão sobre o perfil dos usuários e sua relação como o contexto virtual, bem como a respeito do papel do tutor em todo o processo. O curso ocorreu em plataforma on-line, no período de junho de 2006 a março de 2008, com o conteúdo distribuído em seis Unidades Didáticas. Concluiu-se que capacitações a distância são essenciais para a formação de tutores por proporcionar-lhes conhecimento, habilidades e competências para lidar com as questões inerentes à função que pretendem desenvolver. Palavras-chave: Educação a distância; Ensino; Tecnologia educacional.

\section{QUALIFICATION IN DISTANCE LEARNING: A STUDENT'S REFLECTIONS}

ABSTRACT: This is a reflection about the importance of the on-line teaching-learning process in the training of distance-learning tutors, from the perspective of a student. The study highlights the experience related by a student taking part in this modality of teaching - his view of the profile of course users and his relation with the virtual context, as well as with respect to the role of the course tutor in the whole process. The course took place on an on-line platform between June 2006 and March 2008, with the content distributed among six didactic units. It was concluded that distance learning is essential for the training of tutors, as it provides them with knowledge, abilities and competencies to deal with questions inherent to the role they intend to carry out. KEYWORDS: Distance learning; Teaching; Educational technology.

\section{CAPACITACIÓN EN EDUCACIÓN A DISTANCIA: REFLEXIONES DE UN ESTUDIANTE}

RESUMEN: Esta es una reflexión acerca de la importancia del proceso de enseñanza y aprendizaje on-line para la formación de tutores en Educación a distancia, de acuerdo a la percepción del estudiante. El estudio destaca el relato de la experiencia de un alumno de esta modalidad de enseñanza; su visión sobre el perfil de los usuarios y su relación con el contexto virtual, así como acerca del papel del tutor en todo el proceso. El curso ocurrió en plataforma on-line, en el período de junio de 2006 a marzo de 2008, con el contenido organizado en seis Unidades Didácticas. Se concluyó que capacitaciones a distancia son esenciales para la formación de tutores por proporcionarles conocimiento, habilidades y competencias para lidiar con las cuestiones inherentes a la función que pretenden desarrollar.

PALABRAS-CLAVE: Educación a distancia; Enseñanza; Tecnología educacional.

${ }^{1}$ Enfermeira do Serviço de Epidemiologia do Hospital de Clínicas da Universidade Federal do Paraná-HC UFPR. Mestre em Enfermagem. Tutora do Curso de Especialização em Saúde para Professores do Ensino Fundamental e Médio da UFPR.

${ }^{2}$ Enfermeira. Doutora em Educação. Professora do Curso de Graduação e do Programa de Pós-Graduação em Enfermagem-PPGENF UFPR. ${ }^{3}$ Enfermeira do Serviço de Epidemiologia do HC UFPR. Mestranda em Enfermagem pelo PPGENF UFPR. Tutora do Curso de Especialização em Saúde para Professores do Ensino Fundamental e Médio da UFPR. 


\section{INTRODUÇÃO}

As modificações tecnológicas educacionais ocorridas nas últimas décadas têm ocasionado mudanças expressivas nas formas de viver em sociedade, principalmente no que se refere ao acesso globalizado à informação.

Neste contexto, a educação a distância (EAD) tem se mostrado uma estratégia possível para a educação ${ }^{(1)}$. Entretanto, na mesma proporção em que ela tem crescido e transformado o cenário do ensino, aumentam as necessidades de investimento na formação de profissionais capacitados para intermediar esta proposta pedagógica. Sabe-se que muitos cursos que foram planejados para realização presencial sofreram adaptações para a forma de ensino on-line, utilizando profissionais didaticamente despreparados para a função. A oferta de cursos a distância ainda é deficiente, por falta de tutores que possuam, além de experiência tecnológica, significativa formação pedagógica ${ }^{(2)}$.

Neste sentido, é essencial que o tutor vivencie o processo como aluno, pois, passando pelas etapas e dificuldades que possam existir no decorrer da aprendizagem, poderá ter mais domínio sobre os conteúdos e as ferramentas de interação. A atuação tutorial será decisiva para o sucesso do curso e permanência do aluno até a sua conclusão.

Constata-se, então, que os tutores precisam de habilidades e competências para a prática pedagógica em EAD que ultrapassem os conhecimentos adquiridos ao se qualificar para o ensino presencial. Ciente desta necessidade, alguns Núcleos de Educação a Distância têm oferecido cursos de extensão universitária, voltados à capacitação de profissionais para o desempenho da tutoria a distância. Neste contexto, pretendeu-se refletir sobre a experiência de um cursista em EAD durante seu processo de formação para o exercício da tutoria, às bases teóricas e a importância do processo de ensino aprendizagem on-line.

\section{APRENDIZADO ON-LINE}

Foi possível perceber, ao primeiro contato com o material didático, uma grande diferença entre o modelo educacional presencial e o sistema a distância. Ao começar a formação tutorial houve incentivo para interação com a plataforma virtual e conhecimento do guia didático e das orientações sobre programação, objetivos, metodologia e formas de avaliação. A leitura foi agradável, animada por ilustrações, pausas para reflexão e acesso a textos complementares.

A organização do tempo, sequência e espaço para o estudo foram flexíveis, já que se teve acesso ao conteúdo da unidade didática na íntegra, e tempo suficiente para desenvolver as atividades e propostas para auxiliar no processo de ensino-aprendizagem.

Para apropriar-se do conteúdo, o cursista foi convidado a ler os textos e hipertextos que compunham a Unidade Didática. A leitura conferiu novos conhecimentos e uma rede de significados assimilados de forma muito pessoal, a partir da interpretação de cada um, já que os textos são como diálogos ${ }^{(3)}$. Somaramse aos textos impressos, a possibilidade do hipertexto, que surgiu por meio de links e cliques no mouse, dando novos sentidos ao conteúdo, com dinamismo e rapidez ${ }^{(4)}$. Assim, a leitura do material didático foi particularmente interpretada pelos vários cursistas, contribuindo para a reestruturação e ampliação de suas visões acerca do tema abordado.

Visando enriquecer o aprendizado e fixar o conteúdo, momentos de interação tutor-cursistas foram promovidos, na forma de discussões em fóruns ou chat. O fórum permitiu a comunicação entre os próprios cursistas com a mediação do tutor, bem como a troca de experiências e debates sobre conceitos apresentados pelos participantes, garantindo ampla visão sobre o tema. Esta etapa foi essencial para que os alunos percebessem que não estavam sozinhos no processo, e que, apesar de não compartilhar o espaço físico concreto proporcionado pela sala de aula tradicional, poderiam interagir com colegas virtualmente, expondo sua opinião. Ao término da atividade foi possível entender a importância da aprendizagem colaborativa na construção coletiva do conhecimento. O chat proporcionou a interação entre alunos e tutor, permitindo imediata troca de ideias.

Refletindo sobre a aprendizagem proporcionada pelo sistema de Educação a Distância, pode-se observar que ela acontece em plataforma virtual com o auxílio de várias interfaces. A compreensão do conteúdo se inicia com a leitura dos textos e hipertextos, sob o incentivo do tutor; o conteúdo é apreendido e complementada pela troca de experiências proporcionada pelos fóruns de discussão ou chat e são aprofundados pelos comentários e direcionamentos feitos pelo orientador na avaliação das atividades. Ao final de cada unidade didática, é esperado que o cursista tenha se apropriado do conteúdo teórico, compartilhado suas experiências e exercitado a interatividade, o que auxiliará em sua formação de tutor. 


\section{O ALUNO NO CONTEXTO DA EAD}

Faz-se necessário lembrar que, assim como o sistema de EAD foge aos moldes tradicionais de ensino e aprendizagem, também o aluno desta modalidade apresenta características peculiares que o levam a procurar soluções adequadas e adaptáveis às suas necessidades pedagógicas. Em geral, os cursistas de EAD são adultos que já exercem uma profissão, são independentes e tomaram iniciativa de fazer o curso pela necessidade de atualização ou capacitação. Sendo assim, partem de um conhecimento prévio que deve ser aproveitado como estímulo para novas sínteses e bom aproveitamento do curso.

O aluno de EAD busca a formação ao longo da vida para qualificar-se e manter-se apto a aproveitar as oportunidades de trabalho. Esta modalidade educacional visa a contemplar as populações adultas que não têm condições de frequentar o ensino presencial, seja por questões geográficas, de tempo, ou pessoais, mas que buscam continuar a sua formação ${ }^{(5)}$.

\section{O PAPEL DO TUTOR NO PROCESSO DE APRENDIZAGEM}

Um bom curso, seja presencial ou a distância, não depende somente da maturidade intelectual e emocional de educadores entusiastas e abertos ao diálogo, mas também de alunos curiosos, motivados e parceiros do educador ${ }^{(6)}$. O interesse por EAD e por tecnologia de informação é fundamental, tanto para o tutor quanto para o aluno.

Para ser um bom formador, o tutor precisa conhecer muito além do contexto educacional e pedagógico; precisa conhecer o contexto do aluno, seu cotidiano, e experiências de vida. Como facilitador da aprendizagem, ele deve apontar o caminho educacional a ser percorrido, orientar e propor discussões, mostrando aonde se precisa chegar ${ }^{(7)}$.

O papel do tutor merece destaque, pois suas funções sofrem mudanças na medida em que o curso se desenvolve, passando pela função de ensinar o aluno na utilização do sistema EAD; motivando-o a seguir em frente; desenvolvendo a cultura de trabalhar em grupo e on-line; encorajando a partilha de informações e a contribuição nas discussões acerca do tema; participando na construção do conhecimento; dando feedback e facilitanto a interação entre os alunos, até que estes estejam mais autônomos em sua própria aprendizagem ${ }^{(8)}$.

Desse modo, podemos pensar que cabe ao tutor estar presente em todo o processo de ensino-aprendi- zagem, intermediando a construção do conhecimento individual e coletivo e auxiliando os alunos a desenvolver a responsabilidade necessária.

\section{CONSIDERAÇÕES FINAIS}

O Curso de Aperfeiçoamento para Capacitação de Tutores em EAD proporciona uma experiência indispensável para os profissionais que pensam em fazer parte de um programa de ensino on-line. Para direcionar um estudo de qualidade e ter sucesso, o educador a distância precisa de habilidades para trabalhar em sala virtual e com a internet, pois estas ferramentas contribuirão para o desenvolvimento de práticas como: leitura, escrita, reflexão crítica, interação, e principalmente, correlação entre a teoria e a prática.

Pode-se perceber que a aprendizagem a distância confere certa autonomia ao aluno, o que é necessário também para o educador. As ferramentas de interação como o fórum, o chat $\mathrm{e}$ o correio eletrônico favorecem o contato virtual entre aluno-aluno e aluno-tutor, estreitando as relações entre esses atores e colaborando na desconstrução do paradigma de que a trajetória do cursista em EAD seja solitária.

A proposta de reflexão sobre o processo de ensinoaprendizagem foi decisiva na finalização do curso, favorecendo a revisão e a fixação do conteúdo, reforçando o fato de que a leitura de um texto atribui novos significados ao leitor, a cada momento, bem como sugerindo adequações ao contexto em que é realizada.

Cabe aos educadores repensar o seu papel frente a essa evolução tecnológica-educacional, sua relação com os alunos e a utilização dos meios de informação e aprendizagem existentes no cenário atual, procurando aliar o avanço tecnológico no campo da informática à sua prática de ensino.

\section{REFERÊNCIAS}

1. Ortiz MCL, Ribeiro RP, Garanhani ML. Educação à distância: uma ferramenta para educação permanente de enfermeiros que trabalham com assistência perioperatória. Cogitare Enferm. 2008;13(4):558-65.

2. Clementino A. Gestão pedagógica de cursos em EAD. São Paulo: Editora; 2005.

3. Martins OB, Polak YNS. Curso de formação em educação a distância: planejamento e gestão em educação a distância - organização curricular e material didático. Curitiba: NEAD/UFPR; 2001. 
4. Serviço Nacional do Comércio. Tutoria on-line: processos de ensino e aprendizagem na WEB. Unidade 1. Rio de Janeiro; 2006.

5. Belloni ML. Educação a distância. São Paulo: Autores Associados; 2003.

6. Moran JM. O que é um bom curso a distância? [acesso em: 21 fev 2008]. Disponível: http://www.eca.usp.br/ prof/moran/bom_curso.htm

7. Novas tecnologias no contexto educacional: reflexões e relatos de experiências [Internet]. São Bernardo do Campo, SP: Umesp. A tutoria no contexto da introdução à capacitação docente a distância da Universidade Metodista de São Paulo [acesso em 20 fev 2008]; [aproximadamente 11 p.]. Disponível: http://www.metodista.br/atualiza/ conteudo/material-de-apoio/livros/novas-tecnologias-nocontexto-educacional/aparecida.pdf

8. Morgado L. O papel do professor em contextos de ensino on-line: problemas e virtualidades. Tutoria on-line. SENAC; 2006. 